\title{
Assessment of Time and Costs of Two Formwork Methodologies in the Philippines using BIM Simulation
}

\author{
Jason Maximino C. Ongpeng \\ \# Civil Engineering Department, De La Salle University, 2401 Taft Avenue, Manila City, 1004, Philippines \\ E-mail: Jason.ongpeng@dlsu.edu.ph
}

\begin{abstract}
In the Philippine construction industry, choices of formwork methodology is critical to contractors or client/project managers. Cost and time are the parameters commonly considered to address which method is recommended for a project. In this study, simulation using BIM was made from input parameters taken from actual project observations and data collection from five projects. Two methods were considered: method A (traditional forms) and method B (steel decks). The output parameters after the BIM simulation were processed cost and time. A statistical t-test was conducted for both process costs and time durations to differentiate between the two methods. It was found out that the process costs for overall, columns, and beams of method A were not statistically different from method $B$, while the slab process cost was significantly different. This indicated that only slab process cost was relatively expensive for method B. For the duration, both the columns and beams were not statistically different, while overall and slabs' duration was significantly different. It showed that overall duration and slab process duration is relatively lower for method $B$. This paper showed that BIM simulation could help managers in their decision on choosing the construction methodology to balance cost and time of their project.
\end{abstract}

Keywords — building information modelling (BIM); formworks; steel deck

\section{INTRODUCTION}

In construction, a capital cost that involves complicated activities should be considered. In a recent study in Indonesia, constructing a toll project required relatively high capital investments. Risk management was introduced to determine which of the activities in construction produced the highest probability of a decrease in project cost [1]. One of the critical activities in construction is the formworks. Determining which type of formworks to be used depends on the cost of materials, its construction and assembly, reusability, and strength and resistance to pressure and tear and wear. However, no definite standard operating procedure has been established to determine the most efficient way of designing and using formworks regarding scheduling, spacing, and the size and type of construction. More often engineers use subjective and intuitive opinions in designing and using their formworks.

There are different types of materials used for formworks. In the early years, lumber or timber was widely used as temporary structures in construction. Nowadays, materials such as plywood, steel, plastic, fiberglass and precast concrete are being used. However, for small construction projects, the use of timber as temporary structures are more commonly used, while fiberglass from precast concrete or aluminum is used for slabs and curved surfaces [2]. In the
Philippines, plywood and phenolic boards remain to be the most commonly used sheathings to give shape to concrete structural elements. Some contractors have begun using steel deck and steel formworks, though it is not a practice commonly utilized by the country's engineers. Also, lowrise construction projects that make use of steel formworks are rarely seen, some projects have begun utilizing mixed systems comprised of both wood and steel. It is common knowledge that steel formworks should encourage better productivity, but the barrier in using it is the capital cost.

The appropriate selection of the formwork method is a critical factor in successful project completion. The cost and time spent on a project can be significantly affected if the selected formwork method is not appropriate or not best fitted for it. Nowadays, use of software like CAD is used to help managers to develop modeling decision process [3]. Furthermore, a study on a formwork method selection model using boosted decision trees, specifically for tall building construction was conducted [4]. The validity of their proposed model was compared to other existing selection models (artificial neural network and decision tree), regarding structural type, building height, number of floors, floor area, building shape and degree of repetition.

With the advancement in software, Building Information Modeling (BIM) enables project managers, planners, and quantity surveyors to visualize and simulate an actual project 
to accurately determine and foresee possible problems that may occur and actions needed to be taken in the future. It is considered to be a 5-dimensional tool, wherein the first three dimensions are spatial - length, width, and height - then the fourth and fifth dimension being time and cost, respectively. The progress of a project can be monitored in a BIM software as it progresses through time and cost.

The use of BIM in the construction industry has revolutionized how project specifications and plans are communicated through the owner and the contractor. This growing scale has led many nations to create a regulating committee to standardize the use of BIM in their respective country. In Singapore, application of BIM was used for plan submissions more than $5000 \mathrm{~m}^{2}$ in 2015 [5].

In addition, given that the BIM software can contain information in five dimensions, a study on the software as an aid for project management in the Architectural, Engineering, and Construction (AEC) sector was conducted [6] on the idea of having the documents, such as formwork and reinforcement drawings, shall be integrated with the modelbased information models. With this, visualization of the project can be simulated where comparisons such as targetperformance can be seen. Moreover, construction progress documentation, invoices, and specifications can then be readily available in a single software. Another study focused on a method for capturing, collating, linking data across BIM and building management system data environments. The documentation and metered building performance linked building designers and operators using the feedback mechanism to improve management system [7].

Development and researches on BIM were extensive for the past decades. In the aspect of quality, the use of noncontact dimensional quality assurance technique using laser scanning and BIM in fabrication and assembly stages of modularized prefabricated, precast concrete components was studied [8]. Also, BIM technology was used to analyze safety hazards in the early stages and planning stages of scaffolding activities. Developed algorithms were implemented to commercially available BIM software where a real-world application for reducing safety hazards and documenting preventive measures before an event occurs [9].

Simulations using BIM has been an advantage to the construction industry. BIM-structural framework optimization and simulation system was developed to manage construction scheduling and planning with $3 \mathrm{D}$ geometry data and process data [10]. BIM5D software was used in construction schedule management considering the real environment and personal environment. Some advantages of the technology were: timely progress of the completion of the percentage of the plan, actual use of the number of funds, and budget deviations [11]. Scheduling in construction is a time-consuming activity. The repetitive process of construction can be recognized to generalize process template. A study was made in estimating similarities in construction schedules and process pattern recognition to simplify construction scheduling [12].

Practice and implementing procedures of BIM is vital in the industry. In small and specific scale, BIM adoption of the tapered slip-form system proved to be efficient by defining the procedures, defining the product breakdown structures in a top-down approach, using 3D parametric models [13]. In large scale, BIM adoption was studied across countries with five conceptual models: BIM diffusion, BIM maturity, Diffusion dynamics, policies, diffusion responsibilities [14]. A study was made to develop cloud-based BIM governance solution to ensure effective communication throughout the lifecycle of the project. Three components were proposed for the governance: actors and teams; data management and information communication technologies; processes and contracts [15].

Challenges in the application of BIM is also essential. Definition of motivations plays a vital role to increase positive perception of users. Study of motivations in the use of BIM in China was done with four categories: image motives, reactive motives, project-based economy motives, cross-project economic motives [16]. In the aspect of cost, the proposed method and management model was developed using BIM to arrive at accurate calculations of supporting materials required to reduce the use and waste of this materials efficiently with minimized construction cost [17]. Development of an ontology based on new rules of measurements for cost estimation using BIM in tendering stages was done to improve efficiency [18].

In general, the use of BIM covers a wide array of aspects from barriers/motivations, planning/scheduling, database management, feedback/life cycle, cost, quality, safety, and governance. In this paper, BIM was done to simulate input parameters (crew productivity rate, sequence, materials constraints) collected in ten projects for a limited time of 30 days. The output parameters were processed cost and process duration. It showed that BIM simulation is a powerful and useful tool to decide on what formworks methodology is more efficient according to two parameters time and cost.

\section{MATERIAL AND METHOD}

\section{A. Parameters}

Formwork is one of the important methods in construction because no concrete will be formed into shape without it. It is common knowledge that steel formworks should encourage better productivity, but the barrier to using it is in its cost. In this paper, simulation using collected data from the actual construction site was done using BIM software. Also, Process Cost Model was derived to show cost and time duration of the formworks activities. From reference, Process Cost Model approach is used for measuring quality costs of construction projects. Traditionally, the PAF (prevention, appraisal, failure) model was used for quality costs but have been found to be unsuitable for the construction industry.

The PAF model is, however, more successful in the manufacturing industry. As such, the Process Cost Model is focused more on capturing the quality costs of a particular process rather than the total quality costs of an entire project, which is what the PAF model does. The costs taken into consideration when producing a process cost model involve the cost of conformance and the cost of non-conformance. The costs of conformance are the costs typically associated with performing a specific process such as material cost and labor cost. The cost of non-conformance is the cost involved when repairing defects. 
In the construction industry, the resource input is usually addressed by the amount of time needed to complete a unit of output, and the unit of output is chosen based on the purpose of conducting a productivity study [19]. In most cases, monetary value is used by organizations as either an input or an output, but this method is not an effective way to measure field productivity especially in construction. In Builder's Guide to Measuring Productivity published by the Building and Construction Authority of the Republic of Singapore, a detailed procedure for measuring labor productivity for formwork installation is given. Productivity is measured per structural element with necessary data being the formwork area and the total man-hours involved. Calculations are performed as follows:

Productivity $=\frac{\text { Formwork Area }\left(\mathrm{m}^{2}\right)}{\text { Total Manhours (manhours) }}$

The man-hours are simply taken from the number of laborers involved in all activities related to the installation of the specified formwork area multiplied by the number of hours these laborers worked to accomplish the element. Activities involved in the installation and removal of formworks typically involve cutting the sheathing, installing frameworks and falseworks, applying the sheathings, bracings, and removal of the sheathings. Figure 1 shows the basic activity sequence.

The sequence of activities started with the planning of materials for the needed concrete pouring. It is followed by implementation of formworks such as cutting of sheathing materials for slabs, columns, and beams, framework, and falsework. The next step is applying shearings and bracing for stability followed by concrete pouring and removal of sheathing and bracings. Soon after the concrete had enough strength to carry its weight after proper curing, concrete pouring activity was discarded in this paper to make sure that the comparison of both formworks methodology was consistent with each other.

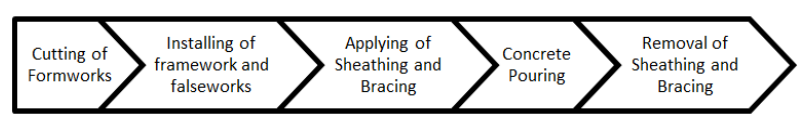

Fig. 1 Sequence of Activities involved in formworks

\section{B. Parameters Methodology}

The objective of the paper is to aid managers in deciding which formwork methodology is advantageous regarding cost and time duration. To achieve the objective, ten ongoing low-rise building construction projects were observed. Five projects focused on conventional formworks for slab while the remaining five focused on steel deck for slab seen in Table 1. Data collected includes productivity of labor, cost process of materials, and construction sequence. Interviews and actual data gathering and observations on construction sequences were noted. For one project location, at least one engineer in charge of the operations was considered. Daily workforce and activities about both the installation and removal of formworks were recorded. Projects A to E corresponds to the Traditional Method while Projects F to J, highlighted in gray, utilizes the Steel Deck.
Traditional method includes the use of timber or lumber formwork for setting up the structure. This material is often used for shuttering which needs its surface to be smooth so as the concrete to have the same texture upon removal [2]. As an example of the traditional method, the data collection for Project B is a two-storey school building with a floor area of $702 \mathrm{~m}^{2}$ holding 10 classrooms. Its columns, beams and slabs are made with plywood sheathings and is classified under method A. The scaffoldings are assembled using coco lumber to reach floors above the ground level. Coco lumber is also known as coconut lumber which is gaining popular interest since it comes from plantation crops and serves as an alternative to rainforest timbers. The sheathings are braced with coco lumber as well until such time that the sheathings can be removed. Carpenters mostly handle formwork installation and removal.

On the other hand, steel deck methodology classified as Method B uses open manufactured steel deck using galvanized iron sheets bended to increase rigidity. As an example, Project F is a six-storey office building with a floor area of around $864 \mathrm{~m}^{2}$. Its columns and beams are made with phenolic board sheathings. The slabs are created using steel deck. It makes use of shoring jacks as falsework to lay the formworks at levels above the ground. Coco lumbers used as stringers to carry the steel deck. The steel deck as forms were not removed after concrete hardening since it is incorporated in the design of slab to withstand dead load and live load during occupancy of the structure.

The collection of the data was done for 30 days. This was done to capture month progress for all ten projects with the given range of accomplishment of the project from $30 \%$ to $70 \%$. This range was set to make sure that the progress curve was already at a constant production rate. Autodesk Revit was used with the available labor productivity collected and the total number of manhours per structural element. Costs were also determined per structural elements such as column, beam, and slab. An overall process cost and duration describing the entirety of the project's formworks was obtained from the BIM simulation.

Assumptions were made in the simulations to compare two different formworks having same limitations. What these comprised constant total skilled and unskilled workers of 10 men in a day, and work in a day is limited to 8 hours. Figure 2 and Figure 3 shows the input and output parameters used in the BIM simulation. Based on the data collected from actual observations and progress reports on site, three input parameters were used. These were the productivity rate for slabs, beams, and columns. The output parameters after BIM simulation included the process cost of each part of the structures (beam, slab, column) regarding unit rate Philippine Pesos per square meter and the total duration regarding unit rate days per square meter. Also, the building models are seen in Figure $4 \mathrm{a}$ and $4 \mathrm{~b}$ for the project name A and $\mathrm{F}$.

After the BIM modeling, process cost was derived. The process cost refers to the cost entailed in performing a particular process. The significance of this is that it allows us to obtain the cost of a single unit of the product or service being produced. In this study, the process considered is the installation and removal of forms. This includes both the material cost and the labor cost needed to perform the 
process. For the comparisons to be consistent, a single price list was used to determine the process cost of all the projects using standard cost estimating at the time of the study.

The process costs were obtained through the use of the scheduling of quantities feature in Autodesk Revit. This allowed us to select particular parameters from each structural element and add calculated values in a tabulated format that could be exported to excel for the more comfortable handling of data. The schedule contains in it the total process cost associated with each structural element in the project accounting for both the material cost and the labor cost. The labor productivity plays a role in determining the labor cost of a project. Once the schedule is produced, it is necessary to export it to Microsoft Excel so that the data were handled easier. Once the excel file is produced it becomes possible to total the process cost of every structural family or the entire project itself, then divide it by the total surface area to express the process cost per $\mathrm{m}^{2}$.

TABLE I

SUMMARIZED DESCRIPTION OF PROJECT

\begin{tabular}{|l|l|l|l|l|}
\hline \multirow{2}{*}{$\begin{array}{c}\text { Designatio } \\
\text { n }\end{array}$} & \multicolumn{1}{|c|}{$\begin{array}{c}\text { Floor } \\
\text { Area } \\
\left(\mathrm{m}^{2}\right)\end{array}$} & $\begin{array}{c}\text { Number } \\
\text { of } \\
\text { Stories }\end{array}$ & $\begin{array}{c}\text { Column/ Beam } \\
\text { Sheathing }\end{array}$ & $\begin{array}{c}\text { Flab } \\
\text { Sheathing }\end{array}$ \\
\hline Project A & 1020 & 4 & Phenolic Board & $\begin{array}{l}\text { Phenolic } \\
\text { Board }\end{array}$ \\
\hline Project B & 702 & 2 & Plywood & Plywood \\
\hline Project C & 466 & 4 & Plywood & Plywood \\
\hline Project D & 302 & 2 & Plywood & Plywood \\
\hline Project E & 362 & 6 & Phenolic Board & $\begin{array}{l}\text { Phenolic } \\
\text { Board }\end{array}$ \\
\hline Project F & 864 & 6 & Phenolic Board & Steel Deck \\
\hline Project G & 70 & 2 & Plywood & Steel Deck \\
\hline Project H & 36 & 2 & Plywood & Steel Deck \\
\hline Project I & 42 & 2 & Phenolic Board & Steel Deck \\
\hline Project J & 188 & 2 & Plywood & Steel Deck \\
\hline
\end{tabular}

The t-test was performed to determine if the differences between the process costs of methods $\mathrm{A}$ and $\mathrm{B}$ were statistically significant or not. A one-tailed t-test was performed because it is expected that method B should come out to be more expensive since steel formwork systems are generally more expensive than wood. Given these, a one-tail t-test ensures that the statistical significance takes into account only one direction in the curve and the probability distribution would not have to be distributed to two tails.

Microsoft Excel was used to determine the p-value of the various sets of data through the T.TEST function. For two sets of data to be considered statistically different from each other, the t-test must return a p-value less than or equal to 0.05 . A t-test that returns a p-value higher than 0.05 shows that the two sets of data being analyzed are not statistically different.
TABLE II

SUMMARY OF LABOR PRODUCTIVITY WITH T-TEST SCORES

\begin{tabular}{|c|c|c|c|}
\hline \multirow{2}{*}{ Designation } & \multicolumn{3}{|c|}{$\begin{array}{c}\text { Labor Productivity } \\
\left(\mathrm{m}^{2} / \text { manhour }\right)\end{array}$} \\
\cline { 2 - 4 } & Column & Beam & Slab \\
\hline Project A & 0.214 & 0.404 & 0.473 \\
\hline Project B & 0.168 & 0.241 & 0.204 \\
\hline Project C & 0.160 & 0.336 & 0.300 \\
\hline Project D & 0.238 & 0.204 & 0.549 \\
\hline Project E & 0.128 & 0.322 & 0.172 \\
\hline Project F & 0.131 & 0.313 & 0.523 \\
\hline Project G & 0.376 & 0.366 & 0.827 \\
\hline Project H & 0.338 & 0.285 & 0.750 \\
\hline Project I & 0.286 & 0.350 & 0.392 \\
\hline Project J & 0.211 & 0.414 & 0.492 \\
\hline t-test & 0.0550 & 0.1612 & 0.0242 \\
\hline Remarks & NIGT & $\begin{array}{c}\text { NOT } \\
\text { SIGNIFICANT }\end{array}$ & SIGNIFICANT \\
\hline
\end{tabular}

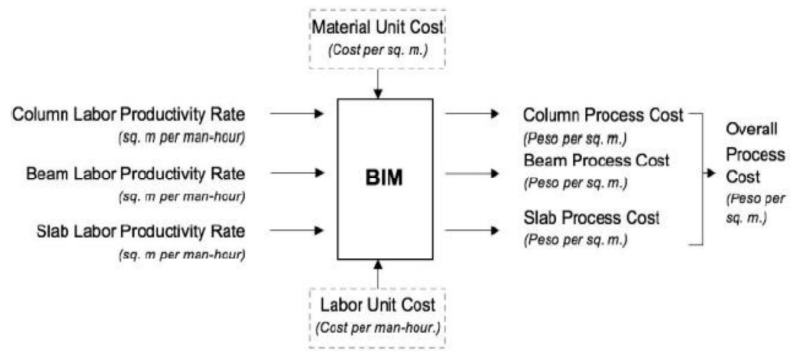

Fig. 2. Flow chart of BIM Inputs and Outputs to optain Process Costs

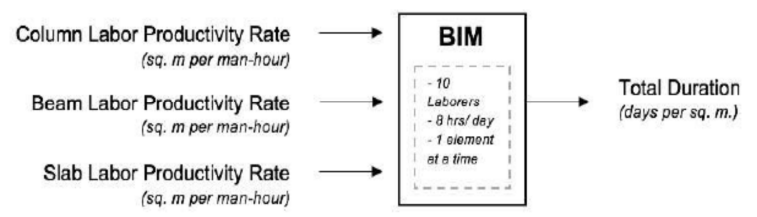

Fig. 3. Flow chart of BIM Inputs and Outputs for Duration

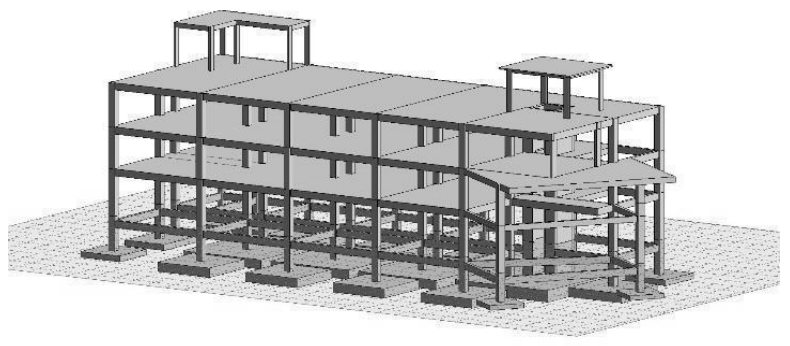

Fig. 4a Structural Revit Model of Project A 


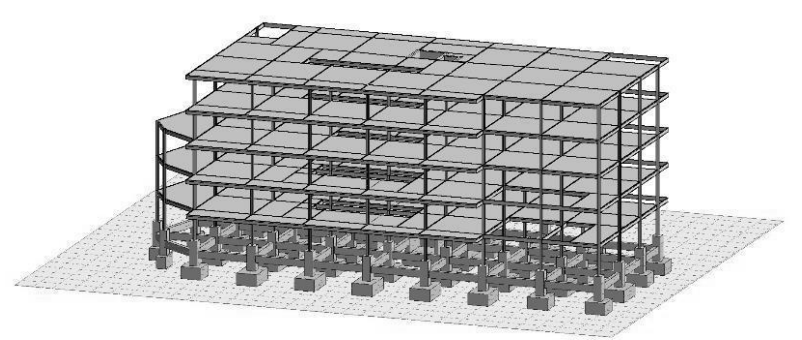

Fig.4b Structural Revit Model of Project F

\section{RESULTS AND DISCUSSION}

Labor productivity was first investigated which is an initial input parameter before the BIM simulation. A statistical t-test was performed to determine if the differences between methods A and B were significant. The $p$-value of the various sets of data was obtained; for two sets of data to be considered statistically different from each other, the t-test must return a p-value less than or equal to 0.05 . A t-test that returns a p-value higher than 0.05 shows that the two sets of data being analyzed are not statistically different.

In Table 2, the difference in labor productivity for columns and beams was not significant, while it had a significant difference in slab works. The highest value for the slab productivity was 0.549 and lowest value of 0.172 for Method A while Method B has 0.827 as the highest value while having a 0.492 value in square meter per person-hour. The box-and-whisker plots of average collected data on labor productivity are seen in Figure 5.

After BIM simulation, process cost for each activity on beam, column, and slab was made. Table 3 exhibits the t-test values, and it was noted that there was no significant difference in the overall process cost, column process cost, and beam process cost. On the other hand, the slab process cost was proved to be significant. The box-and-whisker plots of the BIM simulated process cost for the three are seen in Figure 6. The box-and-whisker plot for overall process cost is seen in Figure 7 where the variance of Method B was relatively more significant than Method A despite having no significant difference.

Time duration is another BIM simulation output. The duration determined in this study only refers to the time it takes for all formwork sheathings to be installed and removed afterward. Concrete pouring and steel rebar construction were excluded.

Duration is another metric obtained from Building Information Modeling with inputs being the labor productivities per family of structural elements. Table 4 shows the generated duration of the project over the total area.

Statistical t-tests were done, and the overall duration and slab formworks were significantly different, while the column and beam had an insignificant difference. Figure 8 is the graphical representation between the outputs of the three structural elements where Method B shows the decreasing trend in project delivery time. In Figure 9, the total overall duration of Method A and Method B can also be observed. The highest value which corresponds to the most extended duration for the slab was 0.0319 and a lowest value or shortest time was 0.0151 for Method B. Method A had 0.0727 as the highest value while having the lowest value at 0.02282 days per square meter.

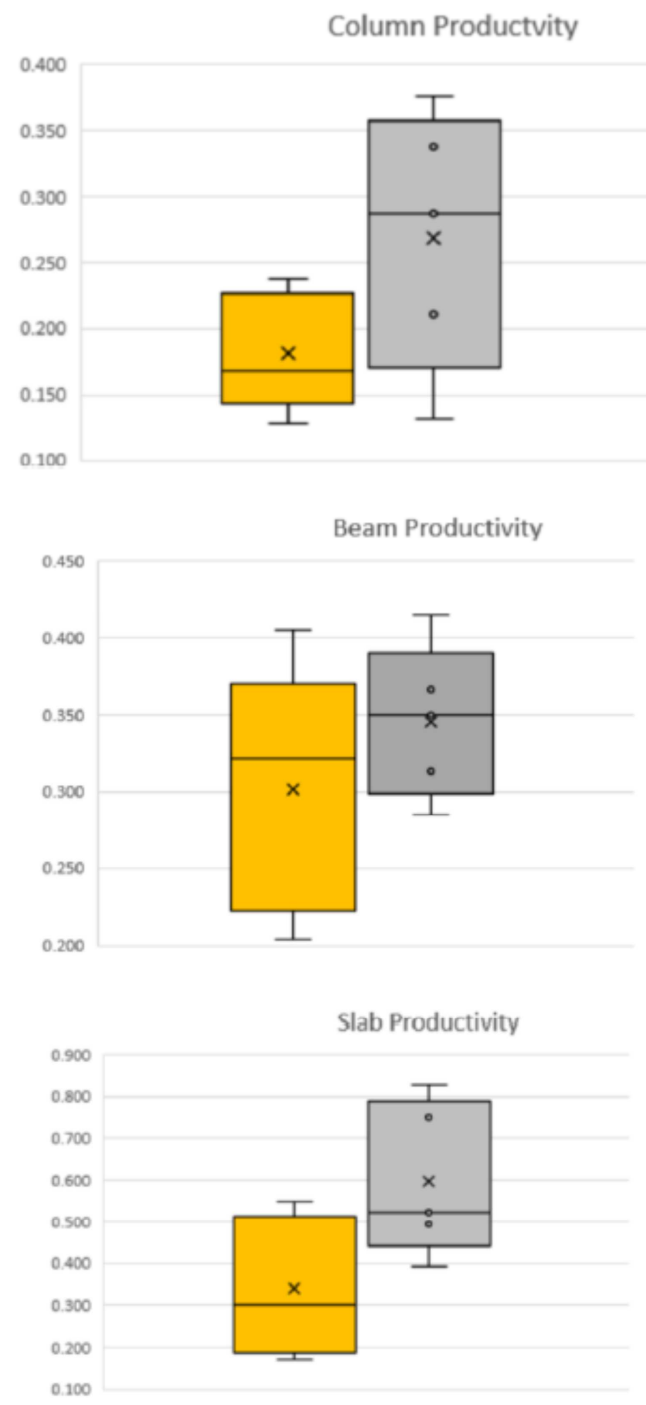

Fig. 5 Box-and-Whisker plots of Labor Productivity in $\mathrm{m} 2 / \mathrm{manhours} \mathrm{(left}$ box for method A and right box for method B)

TABLE III

SUMMARY OF PROCESS COSTS WITH T-TEST SCORES

\begin{tabular}{|c|c|c|c|c|}
\hline \multirow{2}{*}{ Project } & \multicolumn{4}{|c|}{ Process Cost $\left(\mathrm{Php} / \mathrm{m}^{2}\right)$} \\
\cline { 2 - 5 } & All & Column & Beam & Slab \\
\hline A & 299.90 & 386.72 & 268.74 & 247.07 \\
\hline B & 389.07 & 460.80 & 345.39 & 394.38 \\
\hline C & 416.80 & 599.71 & 416.40 & 367.57 \\
\hline D & 385.33 & 389.19 & 422.27 & 242.81 \\
\hline E & 456.39 & 586.22 & 326.92 & 532.20 \\
\hline F & 325.04 & 396.56 & 250.58 & 347.90 \\
\hline G & 677.65 & 524.76 & 917.71 & 431.14 \\
\hline H & 234.43 & 149.77 & 129.36 & 586.21 \\
\hline I & 526.50 & 428.60 & 584.18 & 735.27 \\
\hline J & 432.22 & 361.15 & 359.17 & 656.97 \\
\hline t-test & 0.2795 & 0.0920 & 0.2672 & 0.0303 \\
\hline
\end{tabular}




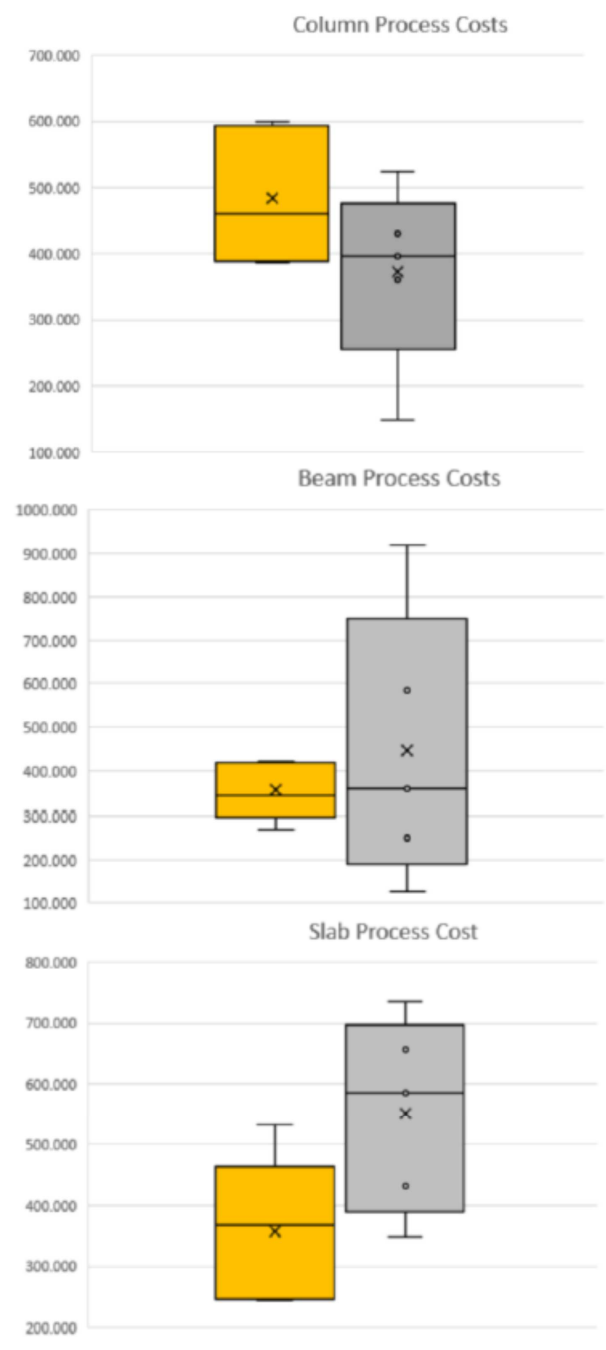

Fig. 6 Box-and-Whisker plot of Process Cost in $\mathrm{PhP} / \mathrm{m} 2$ (left box for method $\mathrm{A}$ and right box for method $\mathrm{B}$ )

TABLE IV

GENERATED DURATION FOR EACH PROJECT

\begin{tabular}{|c|c|c|c|c|}
\hline \multirow{2}{*}{} & \multicolumn{4}{|c|}{ Duration (days/m2) } \\
\cline { 2 - 5 } & All & Column & Beam & Slab \\
\hline A & 0.0384 & 0.0584 & 0.0309 & 0.0264 \\
\hline B & 0.0604 & 0.0744 & 0.0519 & 0.0613 \\
\hline C & 0.0428 & 0.0781 & 0.0372 & 0.0417 \\
\hline D & 0.0528 & 0.0525 & 0.0613 & 0.0228 \\
\hline E & 0.0632 & 0.0977 & 0.0388 & 0.0727 \\
\hline F & 0.0436 & 0.0954 & 0.0399 & 0.0239 \\
\hline G & 0.0299 & 0.0332 & 0.0342 & 0.0151 \\
\hline H & 0.0353 & 0.0370 & 0.0439 & 0.0167 \\
\hline I & 0.0392 & 0.0437 & 0.0357 & 0.0319 \\
\hline J & 0.0397 & 0.0592 & 0.0302 & 0.0254 \\
\hline t-test & 0.0154 & 0.1090 & 0.1300 & 0.0295 \\
\hline
\end{tabular}

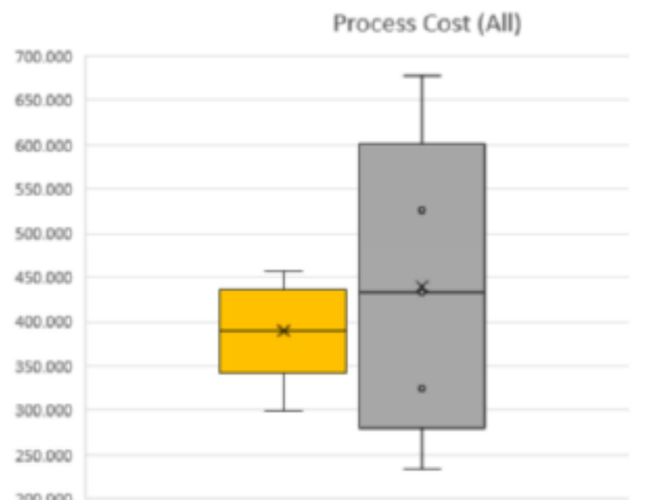

Figure 7. Box-and-Whisker plot of Overall Process Cost in $\mathrm{PhP} / \mathrm{m} 2$ (left box for method $\mathrm{A}$ and right box for method $\mathrm{B}$ )

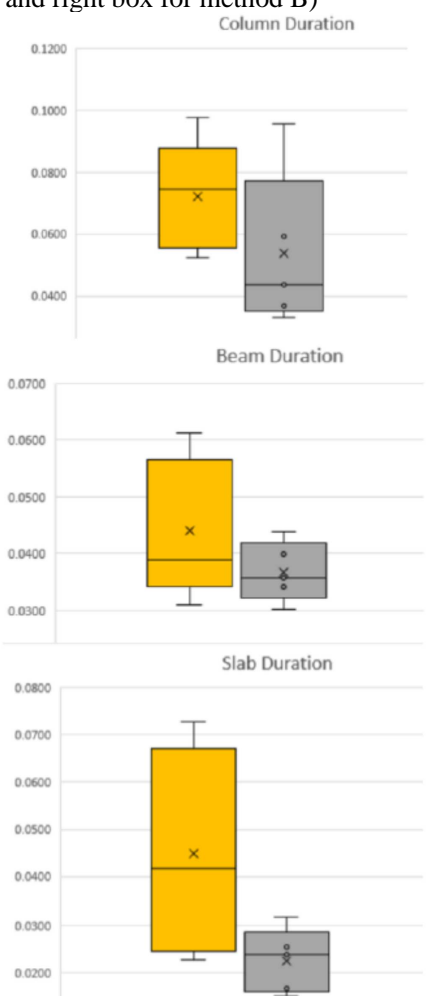

Fig. 8 Box-and-Whisker plots of duration over Total Area in Days/m2 (left box for method A and right box for method B)

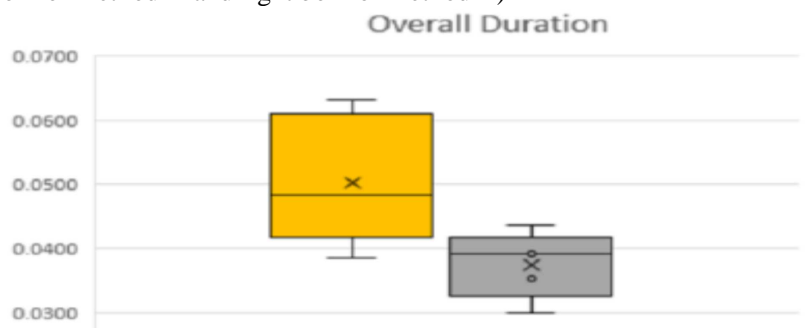

Fig 9 Box-and-Whisker plot of Total Overall Duration over Total Area in Days/m2 (left box for method A and right box for method B)

For the overall duration, both methods had a median of 0.0528 and 0.0392 , respectively. Comparing both methods, it is evident there is a significant difference between the two, with Method B which uses steel decks delivering a shorter duration. 


\section{CONCLUSIONS}

There were two parameters used in the selection of formworks for method A (conventional) and method B (steel deck). It was found out that the process costs for overall, columns, and beams of method A were not statistically different from method B, while the slab process cost was significantly different. This indicated that only slab process cost was relatively expensive for method B. For the duration, both the columns and beams were not statistically different, while overall and slabs' duration was significantly different. It showed that overall duration and slab process duration is relatively lower for method B. Also, through the Building Information Modeling (BIM), Method B was proven to reduce the average time duration of the formworks construction and removal by as much as $31.42 \%$ in turn; it may increase the cost by $11.99 \%$ on average. In particular, this paper showed that BIM simulation could help managers in their decision on choosing the construction methodology to balance cost and time of their project.

\section{ACKNOWLEDGMENT}

I would like to thank De La Salle University Civil Engineering Department administrator, faculty, and staff for their support.

\section{REFERENCES:}

[1] A. Sandhyavitri, I. Talha, M. Fauzi, S. Sutikno,"Managing Construction Risks of the Toll Road Project in Indonesia," International Journal on Advanced Science, Engineering and Information Technology, vol. 7, no. 5, 2017.

[2] C.K. Baxi, Formwork - a concrete quality tool, 36th Conference on Our World in Concrete \& Structures, Singapore Concrete Institute 2011.

[3] Z. Ibrahim, S. B. Mohamed, M. Minhat, A. S. Mohamed, M. R. Musanih, Z. Abd Rahman,"Reason Maintenance in Product Modelling via Open Source CAD System," International Journal on Advanced Science, Engineering and Information Technology, vol. 6, no. 6, pp. 990-996, 2016.
[4] Y. Shin, T. Kim, H. Cho, \& K. Kang, A formwork method selection model based on boosted decision trees in tall building construction, Automation in Construction, 23, 47-54, 2012.

[5] J. Das, Build Smart. Building and Construction Authority Singapore 2011.

[6] F. Opitz, R. Windisch, R.J. Scherer, Integration of document- and model-based building information for project management support. Procedia Engineering, 85, 403-411, 2014.

[7] T. Gerrish, K. Ruikar, M. Cook, M. Johnson, M. Philip, BIM application to building energy performance visualization and management: Challenges and potential, Energy and Buildings 144, 218-228, 2017.

[8] M.K. Kim, Q. Wang, J.W. Park, J.C.P. Cheng, H. Sohn, C-C. Chang, Automated dimensional quality assurance of full-scale precast concrete elements using laser scanning and BIM, Automation in Construction 72, 102-114, 2016.

[9] K. Kim, Y. Cho, S. Zhang, Integrating work sequences and temporary structures into safety planning: Automated scaffoldingrelated hazard identification and prevention in BIM, Automation in Construction 70, 128-142, 2016.

[10] S. Song, J. Yang, N. Kim, Development of a BIM-based structural framework optimization and simulation system for building construction, Computers in Industry 63, 895-912, 2012.

[11] X. Li, J. Xu, Q. Zhang, Research on construction schedule management based on BIM Technology, Procedia Engineering 174, 657-667, 2017.

[12] K. Sigalov, M. Konig, Recognition of process patterns for BIMbased construction schedules, Advanced Engineering Informatics, 2017.

[13] B.Y. Yoo, H.J. Yoon, Y.J. Kim, K.M. Lee, Stepwise application of BIM-based parametric modeling to the tapered slip-form system, Procedia Engineering 145, 112-119, 2016.

[14] M. Kassem, B. Succar, Macro BIM adoption: Comparative market analysis, Automation in Construction, 2017.

[15] E. Alreshidi, M. Mourshed, Y. Rezqui, Factors of effective BIM governance, Journal of Building Engineering 10, 89-101, 2017.

[16] D. Cao, H. Li, G. Wang, T. Huang, Identifying and contextualizing the motivations for BIM implementation in construction projects: An empirical study in China, Project Management 35, 658-669, 2017.

[17] H. Wei, S. Zheng, L. Zhao, R. Huang, BIM-based method calculation of auxiliary materials required in housing construction, Automation in Construction 78, 62-82, 2017.

[18] F.H. Abanda, B. Kamsu-Foguem, J.H.M. Tah, BIM - new rules of measurement ontology for construction cost estimation, Engineering Science and Technology, an International Journal 20, 443-459, 2017.

[19] Y. Su, Construction Crew Productivity Monitoring Supported by Location Awareness Technologies Ph.D., dissertation, University of Illinois, 